\section{Characteristics of Hardwood Cuttings Influence Rooting of Actinidia arguta (Siebold \& Zucc.) Planch.}

\author{
Caula A. Beyl' ${ }^{1}$, Gokul Ghale ${ }^{2}$, and Lianjun Zhang ${ }^{3}$ \\ Department of Plant and Soil Science, Alabama A\&M University, Normal, \\ AL 35762
}

\section{Additional index words. cold-hardy kiwifruit, peewee kiwi, propagation}

\begin{abstract}
Root development of hardwood cuttings of Actinidia arguta was investigated in relation to the size of cuttings and the number of buds. Dormant shoots of 13 Actinidia arguta cultivars and lines were cut into lengths varying from 3.5 to $18 \mathrm{~cm}$ and containing one to nine buds. After being treated with $0.3 \%$ indolebutyric acid in talc, cuttings were stuck into oasis foam cubes and placed under intermittent mist. Actinidia arguta lines and cultivars included 74-46, 74-55, 124-40, 125-40, 127-40, 119-40-B, 'Meader Male', 'Meader Female \#1', 'Geneva \#1', ‘Ananasnaja', 'Michigan State', A. arguta cordifolia (Miq.) Bean 1563-51, and a New Zealand $A$. arguta cordifolia selection. Cultivar significantly affected number of roots, root grade, and length of longest root. In general, cultivars with the highest rooting percentages also had the most and longest roots and the highest root grades. The best cuttings for root formation had eight to nine buds (with three to four in active growth), diameters $<2 \mathrm{~mm}$, and lengths $>10 \mathrm{~cm}$. Cuttings with five to seven buds (with one to three in active growth), diameters between 2 to $8 \mathrm{~mm}$, and lengths $>8 \mathrm{~cm}$ exhibited the best root development in terms of number of roots formed, root length, and root grade.
\end{abstract}

The Actinidiaceae are a family of woody, deciduous, perennial vines containing the genus Actinidia. The most commonly known member of this family is the kiwifruit, Actinidia deliciosa (A. Chev.) C. F. Liang et A. R. Ferguson, but there are many other distinct taxa $(\approx 100)$ within this family that have considerable commercial potential and whose fruit are commonly collected from wild plants in China (Ferguson, 1984). Of these, Actinidia arguta, which we call "peewee kiwi" because of its grape-sized fruit, probably offers the most potential. Commercial plantings of $A$ deliciosa most often consist of plants propagated using cleft or whip and tongue grafts. Softwood cuttings and root cuttings can be used; however, the problem with cuttage is the tendency for kiwifruit cuttings to form excessive callus and few roots, particularly in the case of hardwood cuttings (Sale, 1985). Softwood cuttings root fairly well under mist coupled with bottom heat at 20 to $25 \mathrm{C}$ (Sale, 1984). Monrovia Nursery Co. has achieved a rooting percentage of $75 \%$ from leafy cuttings taken in summer (Conner, 1982).

Received for publication 3 June 1994. Accepted for publication 17 Apr. 1995. Funding for this research was provided in part by U.S. Dept. of Agriculture/ Cooperative State Research Service Grant no. ALAX-011-188. The cost of publishing this paper was defrayed in part by the payment of page charges. Under postal regulations, this paper therefore must be hereby marked advertisement solely to indicate this fact.

${ }^{1}$ Professor.

${ }^{2}$ Graduate Research Assistant.

${ }^{3}$ Assistant Professor. Current address: College of

Environmental Science and Forestry, State Univ. of

New York, Syracuse, NY 13210-2778.
Factors such as diameter and cutting size have received relatively little attention in propagation literature. More often, the focus is on the type of cutting, position on the stock plant, and hormonal and environmental treatments to enhance rooting - not on the relationship between factors, such as size of the cutting or number of buds on subsequent performance with respect to formation and development of roots. In peach [Prunus persica (L.) Batsch.], there is a positive relationship between stem diameter and rooting (Marini, 1983). Terminal cuttings had to be $\leq 3.5 \mathrm{~mm}$ in diameter to obtain 50\% rooting success. For 'Pixy' plum (Prunus insititia L.), the percentage of rooting decreased with increasing cutting diameter when the medium was rapidly draining sand rather than granulated bark (Howard and Ridout, 1991). From data collected in three experiments over 2 years, Howard and Ridout were able to conclude that shorter, thinner shoots collected from hedges had the highest rooting potential. In a study using semihard- wood cuttings of $A$. deliciosa containing one leaf and one bud, the diameter of the cutting had a profound impact on successful rooting, with cuttings 2.0 to $3.9 \mathrm{~mm}$ in diameter rooting at $90 \%$ and those with diameters $>8.0 \mathrm{~mm}$ rooting at only $10 \%$ (Avery and Beyl, 1986).

Actinidia arguta was chosen for this study to determine if morphological characteristics of the cutting influence rooting success. This species of kiwifruit has commercial potential and is commonly propagated by hardwood cuttings with varying degrees of success. A substantial collection of $A$. arguta cultivars and lines was available in the research pomology orchard at Alabama A\&M Univ., Normal, which permitted comparison of rooting performance in response to cutting characteristics among these cultivars. Also, like A. deliciosa, $A$. arguta are prone to excessive callusing when rooted as hardwood cuttings. Cultivar classification using cluster analysis enabled us to compare the rooting class with factors such as callusing and provides an additional tool for studying how cutting characteristics affect rooting for other hard-to-root species.

\section{Materials and Methods}

All of the stock plants used as the source of the hardwood cuttings were established in the pomology research orchard on the campus of Alabama A\&M Univ. in Sept. 1988 as 1-yearold, own-rooted vines (Stanley \& Sons Nursery, Boring, Ore.). Cuttings came either from a planting of six Actinidia species in a randomized complete-block design with four replications of each six-plant unit (six females to two males) or from a planting consisting of nine female, one self-fertile, and three male cultivars, lines, or subspecies of $A$. arguta arranged in a randomized complete-block design with four blocks, each containing four replications of the basic unit. The vines were planted on Decatur silty clay loam amended with $6.72 \mathrm{~kg}$ of dolomitic lime and $29.4 \mathrm{~kg} \mathrm{P} / \mathrm{ha}$, with a spacing of $3.04 \mathrm{~m}$ in the row and $4.56 \mathrm{~m}$ between rows on a three wire t-bar trellis system.

Leafless hardwood cuttings were collected in early Apr. 1991 from female A. arguta cultivars (74-55, 124-40, 125-40, 'Meader Female \#1', 'Geneva\#1', 'Ananasnaja', 'Michigan State', A. arguta cordifolia 1563-51, and a New Zealand A. arguta cordifolia selection),

Table 1. Ranges of size and number of buds of cuttings from the 13 cultivars used in the rooting experiment.

\begin{tabular}{|c|c|c|c|c|c|c|c|}
\hline \multirow[b]{2}{*}{ Cultivar } & \multirow{2}{*}{$\begin{array}{c}\text { No. } \\
\text { cuttings }\end{array}$} & \multicolumn{2}{|c|}{ Bud count (no.) } & \multicolumn{2}{|c|}{ Length $(\mathrm{cm})$} & \multicolumn{2}{|c|}{ Diam $(\mathrm{mm})$} \\
\hline & & Mean & Range & Mean & Range & Mean & Range \\
\hline$\overline{\text { Actinidia arguta cordifolia (NZ) }}$ & 30 & 3.7 & $1-7$ & 7.78 & $5.0-10.0$ & 5.97 & $3.0-10.0$ \\
\hline A. arguta Michigan State & 40 & 2.2 & $1-4$ & 7.28 & $3.5-11.0$ & 5.98 & $3.0-9.0$ \\
\hline A. arguta Meader Female \#1 & 20 & 4.0 & $2-9$ & 8.88 & $6.0-11.5$ & 4.55 & $2.0-7.0$ \\
\hline A. arguta Meader Male & 31 & 3.3 & $1-6$ & 9.31 & $5.5-15.0$ & 5.65 & $4.0-10.0$ \\
\hline A. arguta $125-40$ & 49 & 3.3 & $1-7$ & 8.56 & $5.0-17.0$ & 5.50 & $1.0-10.0$ \\
\hline A. arguta cordifolia $1563-51$ & 41 & 3.4 & $2-5$ & 7.67 & $4.5-10.4$ & 5.49 & $1.0-9.0$ \\
\hline A. arguta $124-40$ & 30 & 2.2 & $1-3$ & 7.78 & $5.0-15.5$ & 6.10 & $3.0-9.0$ \\
\hline A. arguta $74-46$ & 29 & 4.2 & $2-8$ & 8.75 & $6.0-12.0$ & 5.52 & $3.0-8.0$ \\
\hline A. arguta Geneva \#1 & 30 & 2.7 & $2-6$ & 7.80 & $5.0-15.5$ & 6.67 & $3.0-10.0$ \\
\hline A. arguta Ananasnaja & 41 & 3.5 & $2-6$ & 9.91 & $5.3-18.0$ & 4.93 & $1.0-9.0$ \\
\hline A. arguta $119-40-\mathrm{B}$ & 20 & 2.9 & $1-9$ & 7.39 & $4.5-9.8$ & 5.10 & $3.0-8.0$ \\
\hline A. arguta $127-40$ & 30 & 3.0 & $1-7$ & 8.53 & $6.0-13.0$ & 5.03 & $3.0-8.0$ \\
\hline A. arguta $74-55$ & 10 & 3.5 & $3-5$ & 8.36 & $6.2-13.0$ & 4.70 & $3.0-7.0$ \\
\hline
\end{tabular}


male cultivars (127-40, 'Meader Male', 7446), and self-fertile cultivar 119-40-B. Cuttings were trimmed to various lengths, ranging from 3.5 to $18 \mathrm{~cm}$, with diameters ranging from 1 to $10 \mathrm{~mm}$, containing from one to nine buds each. In many cases, the length and diameter of the cutting were dictated by the available wood on the vine. Cuttings were placed in moist storage at $5 \mathrm{C}$ for 2 weeks, and then the basal cut portion of each cutting was dipped into $0.3 \%$ indolebutyric acid in talc and inserted into oasis foam cubes $(3.8 \times 3.8 \times 3.8$ $\mathrm{cm}$; Smithers-Oasis Co., Kent, Ohio). The cuttings were arranged in a completely randomized design of cultivar or subspecies with one to five replications of each 10 -cutting unit. Intermittent mist was used for 6 sec every 6 $\mathrm{min}$, and a 16-h photoperiod was maintained throughout the rooting period using four $40-\mathrm{W}$ incandescent bulbs (General Electric, Lighting, Cleveland, Ohio). The greenhouse air typically ranged between 13 to $28 \mathrm{C}$.

After 1 month, the cuttings were evaluated for percent rooting, and the following data were collected: number of buds, number of growing shoots, length of cutting, diameter of cutting, number of roots, root grade (0 to 9 , where $0=$ dead and $9=$ profuse root development), length of longest root, and amount of callus ( 0 to 5 , where $0=$ no callus, $1=$ little callus, $5=$ abundant callus). The data were statistically analyzed with respect to two features, the variation in rooting performance among the 13 cultivars and the effects of cutting characteristics on rooting success and development.

Analysis of covariance was conducted to detect the difference in rooting performance among the 13 cultivars. Because the cuttings were trimmed to various lengths and were of various diameters (Table 1), contrasts using arithmetic means could be confounded by cutting sizes. Therefore, cutting length and diameter were used as covariates in a covariance model. Least-square means were used for cultivar comparisons, where the three rooting response variables (number of roots, length of longest root, and root grade) were adjusted to the overall means of cutting length and diameter. A cluster analysis also was performed to classify the 13 cultivars into groups based on rooting percentage, number of roots, and length of longest root. Root grade was not used in the analysis because it was highly correlated with the other observations. The CLUSTER procedure of SAS (SAS Institute, 1985) was used with STANDARD and COMPLETE options. For removing arbitrary effects of measuring units, the three rooting criteria were standardized to dimensionless units. The complete linkage method was applied because of its tendency to find relatively compact, hyper-spherical groups composed of highly similar cases (Aldenderfer and Blashfield, 1984).

The four characteristics (cutting length and diameter, number of buds, and number of growing shoots) were categorized into several classes and related to the rooting characteristics. Duncan's multiple range test at $P \leq 0.05$ was used to compare the difference among the classes over all cultivars. Percentage of rooting is reported with the SE of the mean to permit comparison.

\section{Results and Discussion}

Variation in rooting performance among the 13 cultivars. Cluster analysis (Johnson and Wichern, 1992) was applied to classify the 13 cultivars into rooting performance groups according to their ability to root and subsequent root development. This information helped to identify which cultivars were easiest to propagate and whether groups of cultivars from similar backgrounds or collections shared rooting characteristics.

The Euclidean distances (ED) (i.e., similarity measures) between clusters give rise to the dendogram from the cluster analysis (Fig. 1). In general, the 13 cultivars and lines could be categorized into three groups: 1) readily rooting-A. arguta cordifolia NZ, 'Michigan State', 'Meader Female \#1', 'Meader Male', and $125-40 ; 2$ ) moderately rooting $-A$. arguta cordifolia 1563-51, A. arguta 124-40, 74-46, 'Geneva \#1', and 'Ananasnaja'; 3) poorly rooting-A. arguta 119-40-B, 127-40, and 74-55.

Actinidia arguta cordifolia NZ, a selection from New Zealand, was classified as readily rooting, unlike the other $A$. arguta cordifolia that rooted moderately. 'Michigan State' comes from a plant that was on the campus of Michigan State Univ., East Lansing, and was classified as having high rooting ability. 'Meader Female \#1' and 'Meader Male', which came out of a breeding program conducted by E.M. Meader of New Hampshire, were classified as readily rooting. The lines $125-40,124-40,74-$ 46, 127-40, and 74-55, which came out of U.S. Dept. of Agriculture breeding programs, spanned the entire range of rooting ability and showed no commonalities with respect to rooting or root development tendencies. Actinidia arguta cordifolia $1563-51$ and 119-40-B came from the Arnold Arboretum, Jamaica Plain, Mass., collection and were classified as moderately and poorly rooting, respectively. 'Geneva \#1' was taken from the New York Expt. Station, Geneva. 'Ananasnaja' was brought from Belgium in 1972 and might be a cross between A. kolomikta (Maxim. et Rupr.) Maxim. and $A$. arguta.

The three cultivars with the least amount of callus formation ( 0.26 to 0.3$)$ at the bases of the cuttings were $A$. arguta 74-55, $A$. arguta 74-46, and $A$. arguta cordifolia NZ (data not shown). Actinidia arguta 74-55 was classified, using cluster analysis, as a poorly rooting cultivar, and the other two were classified as moderately rooting cultivars. The two cultivars with the greatest amount of callus formation were A. arguta 'Ananasnaja' (ED 1.34) and $A$. arguta 'Meader Male' (ED 1.28) and were classified as rooting moderately and readily, respectively. There did not seem to be a relationship between the amount of callus formation and the overall rooting performance as there was with A. deliciosa (Avery and Beyl, 1986). The amount of callus formation among the A. arguta cultivars was relatively low, which may indicate that excessive callusing is not as severe a problem with $A$. arguta as it is with A. deliciosa.

The cultivars varied in rooting performance, with rooting percentages ranging from only

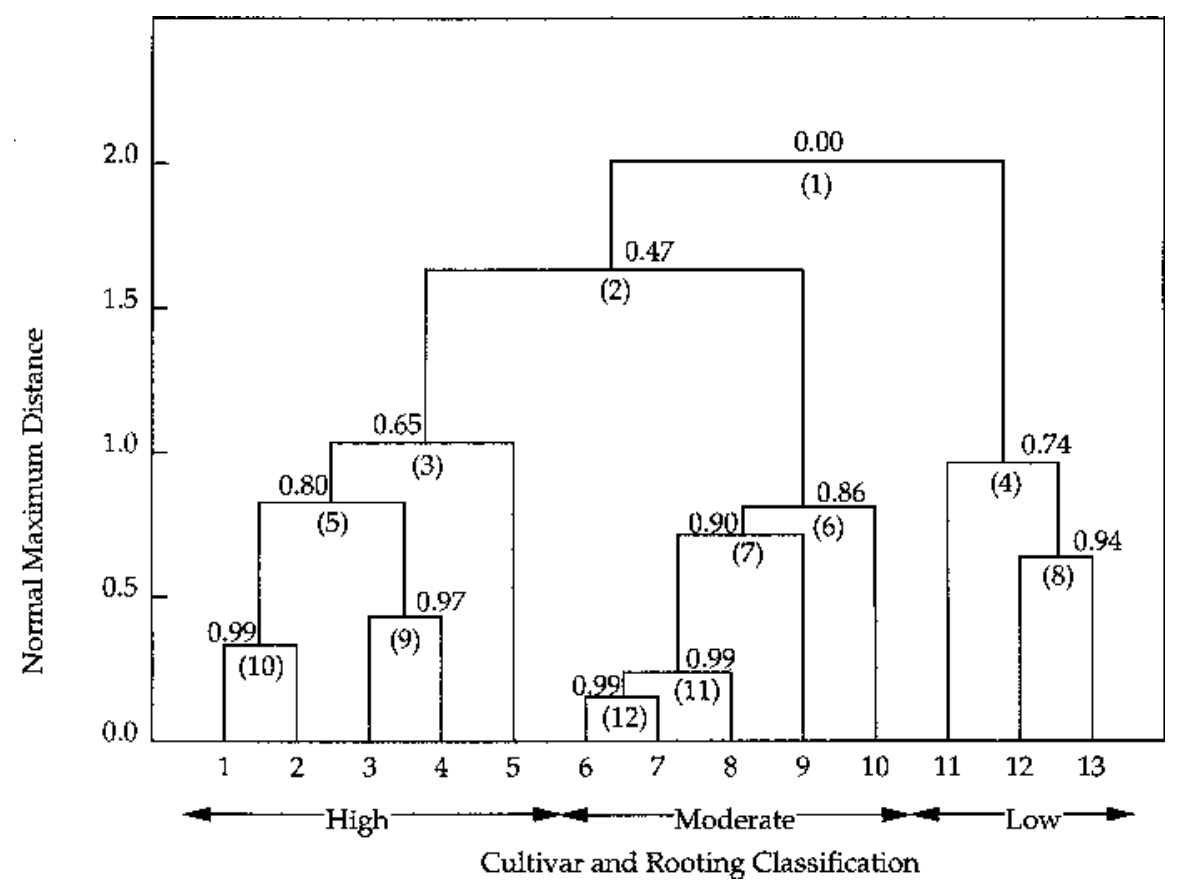

Fig. 1. Dendogram illustrating the relationship among the Actinidia arguta cultivars tested for rooting performance, where 1 = A. cordifolia NZ, 2 = 'Michigan State', $3=$ 'Meader Female \#1', 4 = 'Meader Male', $5=125-40,6=$ A. cordifolia $1563-51,7=124-40,8=74-46,9=$ 'Geneva \#1', 10 = 'Ananasnaja', $11=119-40-\mathrm{B}, 12=127-40,13=74-55$. The number in parentheses is the cluster number; the number immediately above it is the proportion of variance accounted for by the cluster. 
$50 \%$ for A. arguta $74 \%$ to $55 \%$ to $95 \%$ for A. arguta 'Meader Male' (Fig. 2a). Analysis of variance (ANOVA) indicated that there was a significant effect of cultivar on number of roots per cutting, root grade, and length of longest root. Frequently, those cultivars with the highest rooting percentages also were those that performed best with respect to number of roots (Fig. 2b), length of longest root (Fig. 2c), and root grade (Fig. 2d). Although A. arguta 'Ananasnaja' rooted at $85 \%$, it had relatively few roots that contributed to its overall low root grade, but it was among the cultivars with the longest roots $(<2.5 \mathrm{~cm})$.

Rooting success and cutting characteristics. All cuttings with one or 8 to 9 buds per cutting rooted. Number of roots was not significantly affected by number of buds per cutting except for reduced rooting in cuttings with only one bud (data not shown). Length of longest root and root grade were not significantly affected by number of buds per cutting. The greater the number of growing shoots, the greater the percentage of rooting, with $79 \%$ of the cuttings with at least one growing shoot rooting and cuttings that had three or four growing shoots rooting at $94 \%$ and $100 \%$, respectively. Although not significantly different, there was a trend for cuttings with one to three growing shoots to have more roots per cutting and longer roots, which contributed to the significant effect of number of growing shoots on root grade. Cuttings with one to three growing shoots were given root grades $>4$. In general, the more growing shoots (more than three per cutting), the better the response was with respect to number of roots formed, root grade, and length of longest root.

All of the smaller diameter cuttings $(<2$ $\mathrm{mm}$ ) rooted, but the cuttings $<2 \mathrm{~mm}$ had significantly fewer roots (four per cutting) compared to nine to 11 roots per cutting for those with diameters of 2 to $10 \mathrm{~mm}$. Howard and Ridout (1991) reported an increased percentage of rooting with thinner cuttings of plum only when the rooting medium was well-drained. When the medium was too wet, they found an increased incidence of basal necrosis in thinner cuttings. We used oasis foam cubes, which drain well, and saw no basal necrosis. Also, there was no drastic decrease in percentage of rooting for cuttings with a diameter $>8 \mathrm{~mm}$ as reported for $A$. deliciosa (Avery and Beyl, 1986), but the cuttings used in that study contained only one leaf and one bud. Cuttings with a diameter of 0 to $2 \mathrm{~mm}$ and 8 to $10 \mathrm{~mm}$ had a root grade of 1.8 and 2.1, respectively, which was significantly less than the root grade of 4.2 for cuttings with diameters between 2 and $8 \mathrm{~mm}$. This result was a nonsignificant effect of diameter on the longest roots formed on cuttings. The best response in terms of root count and grade occurred with cuttings 2 to $8 \mathrm{~mm}$ in diameter. Potentially, rooting can benefit from cuttings with greater thickness due to high carbohydrate reserves relative to thinner cuttings (Howard, 1980). There seemed to be an optimal thickness, however, of 2 to $8 \mathrm{~mm}$ with $A$. arguta. At $<2 \mathrm{~mm}$, the rooting performance might have been limited by low carbo-
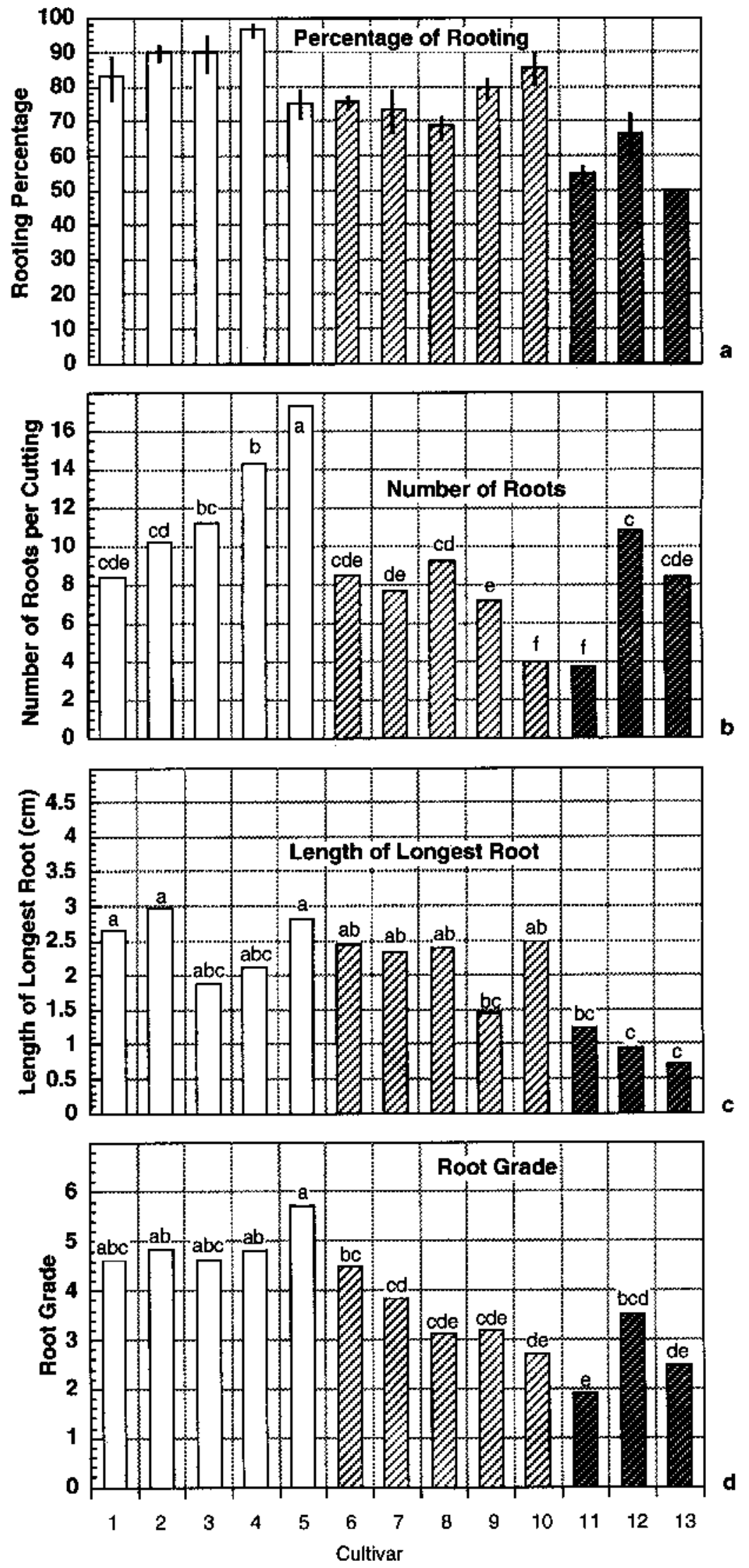

Fig. 2. (a) Rooting percentage, (b) number of roots, (c) length of longest root, and (d) root graderof the 13 cultivars and subspecies of Actinidia arguta tested, where $1=$ A. cordifolia NZ, 2 = 'Michigan State', $3=$ 'Meader Female \#1', $4=$ 'Meader Male', $5=125-40,6=$ A. cordifolia $1563-51,7=124-40,8=74-$ 46,9 = 'Geneva \#1', 10 = 'Ananasnaja', $11=119-40-B, 12=127-40,13=74-55$. Column pattern reflects the rooting class determined using cluster analysis (Fig. 1): $\square=$ readily, $\square Z$ = moderately, and $\mathbb{Z}$ = poorly rooting. Mean separation within columns by LSMEANS at $P \leq 0.05$. The bar at the top of each column for percentage of rooting indicates the SE of the mean. 
hydrate reserves, but cuttings with diameters $>8 \mathrm{~mm}$ did not root as well, which could be a reflection of increased lignification of larger diameter cuttings offsetting any potential benefits of greater carbohydrate reserves.

ANOVA indicated that length of cutting significantly affected all three rooting characteristics. As cutting length increased, the percentage of rooting increased (Fig. 3a). Cuttings $>8 \mathrm{~cm}$ long commonly had the most roots (Fig. 3b), longest roots (Fig. 3c), and highest root grades (Fig. 3d). As cutting length increases so do carbohydrate reserves that are available for development of new roots. This possible effect of carbohydrate reserves was seen in the effect of diameter on rooting performance, but in that case, there was an optimal diameter beyond which rooting performance began to decrease. Increases in the length of cutting do not mean a parallel increase in lignification (as was the case with diameter), so rooting performance did not decrease at the longer lengths.

Cluster analysis permitted classification of cuttings by overall rooting performance and might prove to be a valuable technique for determining potential relationships among cultivars for other characteristics. With respect to how cutting characteristics influenced rooting, those with the highest percentage of rooting were $>10 \mathrm{~cm}$ long and $<2 \mathrm{~mm}$ in diameter and had eight to nine buds with three to four actively growing. But the best overall root development, in terms of number of roots formed, root length, and root grade, occurred with cuttings $>8 \mathrm{~cm}$ long and 2 to $8 \mathrm{~mm}$ in diameter, with five to seven buds with one to three actively growing. This information permits taking only those cuttings with the maximum potential for rooting among the more difficult-to-root cultivars.

\section{Literature Cited}

Aldenderfer, M.S. and R.K. Blashfield. 1984. Cluster analysis. Quantitative applications in the social sciences series \#44. SAGE Publications, Newbury Park, Calif.

Avery, J.D. and C.A. Beyl. 1986. Caliper of semihardwood cutting influences rooting of Actinidia deliciosa. Plant Propagator 32:57.

Conner, D. M. 1982. Cutting propagation of Actinidia chinensis (kiwifruit). Proc. Intl. Plant Prop. Soc. 32:329-333.

Ferguson, A.R. 1984. Kiwifruit: A botanical review. Hort. Rev. 6:1-64.

Howard, B.H. 1980. Propagation of plum rootstocks by winter cuttings. East Malling Res. Sta. Rpt. 1979. Kent, England.

Howard, B.H. and M.S. Ridout. 1991. Rooting potential in plum hardwood cuttings: I. Relationship with shoot diameter. J. Hort. Sci. 66:673680.

Johnson, R.A. and D.W. Wichern. 1992. Applied multivariate statistical analysis. 3rd ed. Prentice Hall, Englewood Cliffs, N.J.

Marini, R P. 1983. Rooting of semi-hardwood peach cuttings as affected by shoot position and thickness. HortScience 18:718-719.

Sale, P.R. 1985. Kiwifruit culture. Government Printer, Wellington, New Zealand.

SAS Institute. 1985. SAS user's guide. Version 5 ed. Cary, N.C.
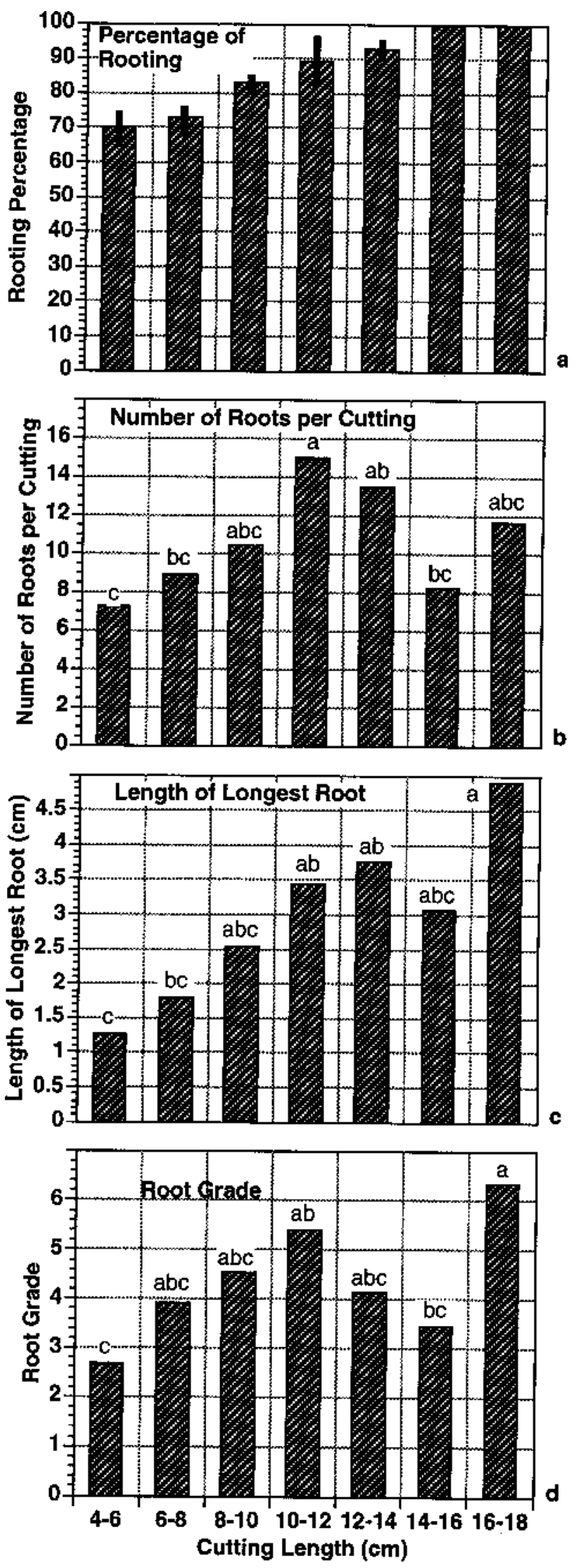

Fig. 3. (a) Rooting percentage, (b) number of roots, (c) length of longest root, (d) and root grade as a function of the length of $A$. arguta cutting. The graph represents data of the pooled rooting responses of the 13 Actinidia cultivars/subspecies screened. Mean separation within columns by LSMEANS at $P \leq 0.05$. The bar at the top of each column for percentage of rooting indicates the SE of the mean. 